\title{
A importância de ferramentas complementares na inserção de processo projetual de Design em MPEs do vestuário
}

The Importance of Complementary Tools Insert in the Design Project Process of Micro and Small Fashion Apparel Companies.

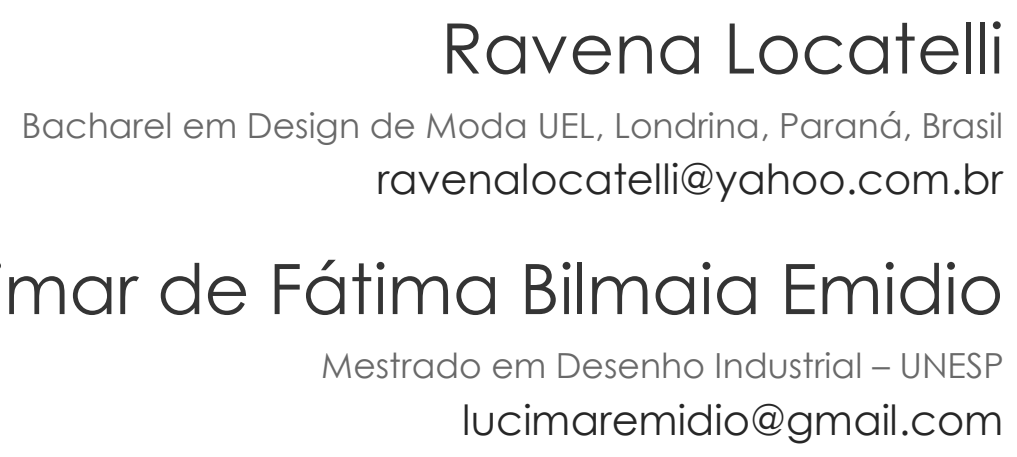

Lucimar de Fátima Bilmaia Emidio lucimaremidio@gmail.com 


\section{A importância de ferramentas complementares na inserção de processo projetual de Design em MPE's do vestuário \\ The Importance of Complementary Tools Insert in the Design Project Process of Micro and Small Fashion Apparel Companies.}

Ravena Locatelli e Lucimar de Fátima Bilmaia Emidio

\section{Resumo}

Considerando a importância de estabelecer uma relação entre a gestão de design e o processo de desenvolvimento de produtos, este trabalho, apresenta um conjunto de ferramentas complementares, e suas principais contribuições durante a implementação de um processo projetual de design de moda em uma MPE do vestuário feminino. Apresenta-se fundamentado em pesquisa bibliográfica e estudo de caso, que pelo resultado alcançado instigou-se a importância de sua disseminação por meio deste artigo.

Palavras- chave: MPE; Processo Projetual de Design de Moda; Ferramentas Complementares.

\begin{abstract}
Considering the importance of establishing a relationship between design management and the process of product development, this paper presents a set of complementary tools, and his major contributions during the implementation of a fashion design process in a fashion female clothing MPE. It's presented based on literature review and case study, the achieved result is instigated the importance of its dissemination through this article.
\end{abstract}

Keywords: MPE; Projetual Fashion Design Process; Complementary tools. 


\section{Introdução}

As empresas de vestuário de moda, por trabalharem com produto sazonal, de ciclo de vida curto com alta carga simbólica e apelo estético, exigem certo nível de complexidade que se materializa em processos a serem controlados e coordenados a partir de conhecimento multidisciplinar, incluindo métodos gerenciais, projetuais, entre outros.

Em MPEs do vestuário de moda, em geral, as informações e experiências relacionadas ao planejamento e desenvolvimento de produtos, ocorrem de forma assistemática e sem registros. Normalmente, a estrutura organizacional destas empresas é assinalada como informal e intuitiva, as decisões também são tomadas dentro da mesma conjuntura e comumente em espaço temporal de curto prazo.

Um dos grandes desafios que os administradores destas empresas enfrentam é deixar de praticar a repetição de ações do passado, que na grande maioria não garantem resultados positivos no futuro.

Para Mauri (1996) torna-se imperativo às mesmas adotarem ações estratégicas que contemplam a gestão desta complexidade, dos aspectos criativos, da tensão gerada quando se inova, da atenção pelo produto no sentido mais amplo e complexo do termo, da propensão natural de agir como mediador entre produção e consumo, evidenciados no design.

Sendo assim, tratando da complexidade e a amplitude de aspectos que exigem conhecimentos multidisciplinares no segmento do vestuário de moda, entende a relevância de propor modelos de referência que contemplem a construção de parâmetros metodológicos para uma prática fundamentada, prioritariamente, em informações que sirvam para subsidiar o processo de tomadas de decisões, tanto de designers quanto gestores.

De acordo com Martins e Van Der Lin (2012) é fato que as informações para a solução de problemas projetuais aparecem de maneira tão rápida, que, assim como os professores de projeto, as empresas que não disporem de métodos e meio auxiliares não poderão ou não saberão utilizar tais informações.

Segundo Sanches (2012), o trajeto projetual será facilitado se for visualizado de maneira panorâmica, analisando de modo sistêmico e sintetizado em critérios objetivos. 
Assim, as vinculações entre as variáveis serão claras e as decisões sobre os procedimentos mais precisas.

Nesse cenário, a atividade de design deve ser desenvolvida a partir de diferentes níveis e de conhecimentos e passa a compor uma estratégia empresarial orientada para a gestão de design, que segundo Gorb (1990) é o conjunto de técnicas de gestão empresarial, juntamente com atividades estratégicas dos designers e dos recursos disponíveis, para atingir objetivos de uma empresa e moldar o perfil da marca, produtos e serviços.

Em vista disto, este estudo, apresenta um conjunto de ferramentas complementares, e suas principais contribuições durante a implementação de um processo projetual de design em uma MPE do vestuário de moda. Apresenta-se fundamentado em pesquisa bibliográfica e estudo de caso, que pelo resultado alcançado instigou-se a importância de sua disseminação por meio deste trabalho.

\section{Gestão de Design}

Mozota (2011) afirma que o campo de design possui afinidade com a gestão por serem atividades que seguem um processo sistemático, lógico e ordenado que objetive a resolução de um problema.

Levar qualquer produto ao mercado requer a colaboração de muitas pessoas com conhecimentos, competências e habilidades diferentes.

O produto e/ ou serviço de design também é submetido à gestão do processo criativo de design. Gerenciar a atividade de design, para que tenha um impacto positivo e atue holisticamente em relação a todos esses contextos internos e externos, disciplinas e funções, relações e conexões, é um dos principais desafios enfrentados por quem aprende a trabalhar no contexto atual do design, das empresas e das indústrias criativas (BEST, 2012, p.40-53).

O papel do gestor de design é interligar os vários setores da empresa. Desse modo, o profissional poderá contar com uma estrutura planejada para alcançar objetivos reais e precisos (COSTA apud TREPTOW, 2013, p.64). O design de um produto é um processo complexo e real, que tem mais alicerce na gestão de informações do que na intuição do designer (TREPTOW, 2013, p.63). 
Ainda sob o olhar da mesma autora, para que um produto e/ ou serviço tenha efetividade para a indústria são necessários três requisitos: a) Produtivo: produção industrial tecnicamente possível; b) Mercadológico: aceitabilidade e consumo pelo público-alvo; c) Financeiro: capacidade de retorno lucrativo do investimento.

A gestão de design é considerada uma estratégia coorporativa que acarreta a mudança organizacional, gestão da inovação e coordenação de recursos. Portanto, a mesma é responsável pela comunicação da relevância do design e implementação do mesmo em segmentos da indústria criativa.

A integração do design em uma empresa pode atingir três níveis de decisões: estratégico, tático e operacional. Para melhor entendimento dos níveis de inserção da gestão de design e sua cadeia de valores, utiliza-se a tabela desenvolvida por Hetzel (apud MOZOTA, 2011, p.15-33).

Tabela 1 - Gestão de Design sobre os três níveis de especialidade.

\begin{tabular}{|c|c|c|c|}
\hline $\begin{array}{l}\text { Níveis de } \\
\text { Decisão }\end{array}$ & Influência do Design & $\begin{array}{c}\text { Níveis de Criação de } \\
\text { Valor }\end{array}$ & Níveis de Competência \\
\hline $\begin{array}{l}\text { Gestão de } \\
\text { Design } \\
\text { Operacional }\end{array}$ & $\begin{array}{l}\text { Sobre a oferta: dá um } \\
\text { sentido ao discurso e ao } \\
\text { objeto. }\end{array}$ & $\begin{array}{l}\text { Atua sobre a oferta da } \\
\text { organização ou função } \\
\text { diferenciadora } \\
\text { design. }\end{array}$ & $\begin{array}{l}\text { Design ação ou como } \\
\text { competência econômica. Cria } \\
\text { o valor sobre as funções da } \\
\text { organização. }\end{array}$ \\
\hline $\begin{array}{c}\text { Gestão de } \\
\text { Design Tático }\end{array}$ & $\begin{array}{l}\text { Sobre os homens: mobiliza } \\
\text { e motiva pela facilidade de } \\
\text { circulação de informações, } \\
\text { aproximando diferentes } \\
\text { atores num mesmo projeto. }\end{array}$ & $\begin{array}{lrr}\text { Atuação } & \text { sobre } & \text { a } \\
\text { empresa ou } & \text { função } \\
\text { coordenadora } & \text { do } \\
\text { design. } & & \end{array}$ & $\begin{array}{l}\text { Design função ou como } \\
\text { competência controladora. } \\
\text { Cria o valor sobre as funções } \\
\text { de suporte, gestão da } \\
\text { inovação e da tecnologia. }\end{array}$ \\
\hline $\begin{array}{l}\text { Gestão de } \\
\text { Design } \\
\text { Estratégico }\end{array}$ & $\begin{array}{l}\text { Sobre a empresa: facilita a } \\
\text { formulação de um projeto } \\
\text { que incite a visão do núcleo } \\
\text { estratégico. }\end{array}$ & $\begin{array}{lr}\text { Atuação do } & \text { design } \\
\text { sobre o ambiente } \\
\text { empresarial ou função } \\
\text { transformadora } \\
\text { design. do }\end{array}$ & $\begin{array}{l}\text { Design visão ou como } \\
\text { competência } \\
\text { Influi na compreensão do } \\
\text { ambiente e transforma } \\
\text { procedimentos. }\end{array}$ \\
\hline
\end{tabular}

Fonte: MARTINS (2004, p.99)

A tabela 1, acima, específica a ação de cada nível de decisão da gestão de design, em sua respectiva linha de funcionamento no que diz respeito a influência, criação de valor e níveis de competência. Por exemplo: o posicionamento estratégico de uma empresa pode definir toda sua estrutura corporativa. Quando o posicionamento estratégico de uma empresa é reativo, o mercado determina sua política de design; quando é proativo, a empresa é capaz de influenciar o mercado e vê o design como ferramenta para criar nova demanda (HART et al., apud MOZOTA, 2011, p.15-33) 


\section{As ferramentas complementares: contribuições para inserção do processo} projetual de design em MPE do vestuário de Moda por meio de um estudo de caso

A empresa Skarab escolhida para realização deste estudo atua há 21 anos no segmento de confecção feminina, com a distribuição de produtos no atacado na cidade de São Carlos e região, estado de São Paulo e trabalhava com um sistema organizacional arcaico e empírico dificultando o acompanhamento do mercado atual.

A primeira necessidade detectada foi a de compreender seu funcionamento e organização e ferramenta escolhida para este fim foi o briefing. Este foi aplicado junto à proprietária, visando identificar a real postura da marca em relação ao mercado, permitindo contextualizar toda a empresa por meio de 8 itens: histórico; imagem de marca; público-alvo; empresa; processo produtivo; produto; revendedores, representantes e concorrentes, conforme descritos a seguir:

Histórico: a MPE Skarab foi fundada em 1993, na cidade de São Carlos-SP, com o objetivo de confeccionar produtos do vestuário feminino, masculino e infantil para venda de atacado na cidade e região. Com o decorrer dos anos o foco da empresa passou a ser apenas o gênero feminino. Em função da mudança acrescentou-se a abordagem plus size, em alguns dos seus produtos que possuem muita influência da alfaiataria.

A marca: o nome da marca surgiu da afinidade da proprietária com o misticismo do Antigo Egito. O escaravelho (scarab em inglês), que é visto como representante terreno do ciclo solar tornou-se um símbolo iconográfico e ideológico incorporado na sociedade do Antigo Egito, sendo sinônimo de sorte e ressureição. Carregando o próprio nome como amuleto da sorte a Skarab propõe ser o diferencial na vida das mulheres em situações adversas e inesperadas, ou seja, criar produtos que sirvam como amuleto da sorte dessas mulheres para que tenham confiança e desenvoltura defronte estas situações sempre com muita feminilidade e modernidade. Apesar deste contexto a proprietária possuía dificuldades em difundir e manter esta imagem, e apresentava produtos que são contraditórios à proposta da marca.

Público-alvo: definido pela proprietária e estilista da marca o público são mulheres de 25-55ano, das classes A, B, C do interior do estado de São Paulo, na região 
da cidade de São Carlos que é uma cidade conhecida por ser: (i) capital do clima; (ii) capital da tecnologia e (iii) cidade do conhecimento. Mulheres com o nível de escolaridade que varia entre ensino médio incompleto à nível superior completo; inseridas no mercado de trabalho. Possuem perspectivas nos relacionamentos pessoais e familiares, na sua maioria com filhos pequenos ou jovens. Vivem um rotina versatilidade e buscam produtos de qualidade; cultivam a boa aparência e são adversas a produtos muito ousados.

Empresa: situa-se na cidade de São Carlos-SP. Trata-se de uma micro empresa familiar, atualmente com 10 funcionários, incluindo a proprietária, que dividem-se em 3 setores, sendo: 1) de desenvolvimento e manutenção comercial e financeira, modelagem e corte, estoque de tecidos e peças; 2) de produção e acabamento das peças; 3) de passadoria e embalagem das peças.

Processos Produtivo: é centralizado com todas as etapas dentro da empresa. $\mathrm{O}$ processo criativo da marca sofre com a falta de tempo e excesso de atividades da responsável (proprietária e estilista), opta-se por mídias prontas como revistas, blogs e telenovelas, ocasionando reproduções de produtos. Logo se inicia a modelagem, enfesto e corte (responsabilidade da proprietária). Em seguida, inicia-se a confecção dos produtos, a gerente de produção detém todas as informações e organiza as tarefas, sendo essencial sua presença durante a confecção. A empresa optou por isentar-se de beneficiamentos como tingimento, estamparia ou qualquer processo terceirizado por serem de cunho inviável em relação ao custo e ritmo da mesma. A marca apresenta dificuldades no controle da quantidade das peças produzidas mensalmente, no entanto, estima-se que produz entre $700-800$ peças/mês.

Produto: a marca não trabalha com o desenvolvimento de coleções. Produz semanalmente novos modelos fora de um contexto específico. Ressalta-se que a mesma pessoa responsável pela venda é também responsável pela criação dos produtos, o que contribui muito para se produzir prioritariamente a partir do que os revendedores desejam.

Os produtos são feitos de forma muito artesanal, já que a empresa não dispõe de toda tecnologia e maquinaria avançado; em seguida são passados, dobrados, etiquetados, embalados e colocados em sacolas divididas por modelos. Utiliza-se de tecidos planos com elastano e malhas, comprados a cada mudança de estação. 
Revendedores e Representantes: os principais clientes da marca são revendedores (lojistas) de multimarcas de São Carlos e região. As vendas são feitas no atacado, pela proprietária que detém a decodificação de preços e todas as informações necessárias, o que torna a MPE dependente da mesma. A Skarab apresenta flexibilidade quanto a quantidade mínima para compra e/ou grade de tamanhos. Segundo a proprietária, o trabalho com representantes apresenta-se inviável pelo acréscimo de custo que há sobre as peças, e por problemas já enfrentados pela falta de profissionalismo de alguns destes profissionais.

Concorrentes: os principais concorrentes da marca são confecções do bairro Bom Retiro da capital São Paulo, que vendem produtos à baixo custo, que apesar da qualidade inferior disputam a atenção do revendedor. Confecções na região de PassosMG que fornecem produtos plus size com detalhes regionalistas e confecções em São José do Rio Preto que produzem produtos com mais conteúdo de moda e aparentemente mais elaborados.

Para a conclusão desta etapa de levantamento da empresa, além desta ferramenta apresentada, utilizou-se também de um diagnóstico, denominado "Modelo de Checagem da Utilização de Design pela MPE” proposto por Emidio (2012), conforme o Anexo A.

De posse de tais dados coletados a partir de ambas as ferramentas, pode-se realizar análise detalhada sobre a empresa. Neste caso específico, os resultados permitiram visualizar os pontos fortes e fracos da empresa com expressiva clareza. Além disso, identificou-se também a pró-atividade e a mudança como fatores favoráveis para o sucesso da mesma. No entanto, a maior dificuldade detectada foi a falta de métodos sistêmicos, ou seja, no processo criativo, projetual e de gestão.

\section{Contribuições para empresa a partir dos resultados iniciais}

Diante disso, pautado em fundamentos teóricos e projetuais acadêmicos, e acompanhando a colocação de Montemezzo (2003), de que o uso de métodos sistemáticos podem contribuir significativamente para a canalização das variáveis que envolvem um problema de design, como contribuição do estudo para aquela empresa, sugeriu-se um novo processo projetual, considerando suas especificidades, conforme apresentado no Anexo B. 
Considerando a importância da validação do novo processo de design para a empresa, propôs-se o desenvolvimento de uma coleção de vestuário de moda para o inverno de 2015, por meio da qual prospectou-se a assertividade do processo projetual proposto, e segundo a empresa contribuiu para assumir uma nova estratégia de desenvolvimento de produtos e processos.

No entanto, durante a fase de implementação do novo processo projetual de design na mesma, identificou-se dificuldades na compreensão das ações a serem realizadas em cada etapa. Detectou-se a necessidade de um amparo por meio de ferramentas, planilhas e tabelas que subsidiassem as decisões e direções a serem tomadas com relação: necessidade de análise estratégica do histórico de vendas realizadas até então; do redesign da marca; de um instrumento que facilitasse o processo de aprovação dos modelos; de uma síntese projetual, entre outros.

Além disso, constatou-se também as contradições na definição do público-alvo pela empresa, fato que exigiu o redirecionamento de público por meio de pesquisas, que possibilitaram realizar o levantamento das dificuldades destas mulheres consumidoras da marca, quanto a configuração de produtos de moda. Por isso, adotou-se a estratégia apresentada na sequência, para realizar a "leitura e interpretação" do mesmo.

\section{O redirecionamento de público-alvo e redesign da marca: estratégias adotadas}

No briefing observou-se que a empresa Skarab definia seu público de maneira ampla e com algumas contradições, o que dificultava a leitura e interpretação do mesmo. Na busca por esclarecimento e compreensão do seu real público, realizou-se uma pesquisa com a aplicação de um questionário, denominado Questionário 1, direcionado às mulheres de São Carlos e região; divulgado on-line e por meio da abordagem pessoal, destes foram obtidas 135 respostas.

$\mathrm{Na}$ sequência, seguindo o modelo de pesquisa de grupo focal (pesquisa de caráter qualitativo que resume-se à pequenos grupos de pessoas reunidos submetidos à questionamentos para avaliar conceitos e identificar problemas), foram selecionados questionamento e imagens de tops e bottons, com conteúdos nos contextos: básico, fashion e vanguarda, constituindo assim o Questionário 2, aplicado junto à 9 mulheres que consomem produtos da marca com frequência, em um ambiente propício a casualidade. 
Posteriormente foram cruzadas as respostas obtidas no Questionário 1, com as respostas do Questionário 2; após a análise do resultado desta relação, realizou-se o levantamento dos modelos mais vendidos pela empresa nos últimos 5 anos, conforme Tabela 2, a seguir, segregado pelos modelos de inverno, verão e aqueles produzidos independente da estação do ano.

Tabela 2 - Histórico de vendas

\begin{tabular}{|c|c|c|c|}
\hline Período & $\begin{array}{l}\text { Produzido independente } \\
\text { da estação }\end{array}$ & $\begin{array}{l}\text { Primavera } \\
\text { Verão }\end{array}$ & $\begin{array}{l}\text { Outono } \\
\text { Inverno }\end{array}$ \\
\hline Há 5 anos & $\begin{array}{l}\text { Calça cigarrete } \\
\text { Calça reta } \\
\text { Camisas mangas curtas/ } \\
\text { longas }\end{array}$ & $\begin{array}{l}\text { Bermuda no joelho justa } \\
\text { Regata básica }\end{array}$ & $\begin{array}{l}\text { Calça reta } \\
\text { Casacos retos } \\
\text { Conjuntos de agasalho }\end{array}$ \\
\hline Há 3 anos & $\begin{array}{l}\text { Calça cigarrete } \\
\text { Calça reta } \\
\text { Saia lápis } \\
\text { Camisas mangas longas }\end{array}$ & $\begin{array}{l}\text { Bermuda } 3 \text { dedos acima do } \\
\text { joelho } \\
\text { Shorts no meio da coxa } \\
\text { Regata básica }\end{array}$ & $\begin{array}{l}\text { Calça montaria } \\
\text { Casacos retos } \\
\text { Blazers }\end{array}$ \\
\hline Há 2 anos & $\begin{array}{l}\text { Calça cigarrete } \\
\text { Calça flaire } \\
\text { Camisas mangas curtas/ } \\
\text { longas }\end{array}$ & $\begin{array}{l}\text { Bermuda } 3 \text { dedos acima do } \\
\text { joelho } \\
\text { Shorts no meio da coxa } \\
\text { Regata básica } \\
\text { Blusas de ombro caído } \\
\text { Vestidos }\end{array}$ & $\begin{array}{l}\text { Calça montaria } \\
\text { Casacos estruturados/ } \\
\text { cinturados } \\
\text { Blazers } \\
\text { Vestidos alfaiataria } \\
\text { Conjuntos de casaco/ blazer } \\
\text { com calça/ saia }\end{array}$ \\
\hline Há 1 ano & $\begin{array}{l}\text { Calça cigarrete } \\
\text { Calça pantalona } \\
\text { Camisas mangas curtas/ } \\
\text { longas }\end{array}$ & $\begin{array}{l}\text { Bermuda } 3 \text { dedos acima do } \\
\text { joelho } \\
\text { Shorts no meio da coxa } \\
\text { Regata básica } \\
\text { Chemisier } \\
\text { Vestidos }\end{array}$ & $\begin{array}{l}\text { Calça montaria } \\
\text { Casacos estruturados/ } \\
\text { cinturados } \\
\text { Blazers } \\
\text { Vestido alfaiataria } \\
\text { Chemisier } \\
\text { Calça pantalona }\end{array}$ \\
\hline Atualmente & $\begin{array}{l}\text { Calça cigarrete } \\
\text { Camisas } \\
\text { curtas/longas }\end{array}$ & $\begin{array}{l}\text { Bermuda } 3 \text { dedos acima do } \\
\text { joelho } \\
\text { Shorts no meio da coxa } \\
\text { Regata básica } \\
\text { Chemisier } \\
\text { Vestidos }\end{array}$ & $\begin{array}{l}\text { Calça montaria } \\
\text { Casacos estruturados/ } \\
\text { cinturados } \\
\text { Blazers } \\
\text { Vestido alfaiataria } \\
\text { Chemisier } \\
\text { Calça pantalona }\end{array}$ \\
\hline $\begin{array}{l}\text { Produtos } \\
\text { de } \\
\text { destaque }\end{array}$ & $\begin{array}{l}\text { Calça cigarrete } \\
\text { Camisas mangas curtas/ } \\
\text { longas }\end{array}$ & $\begin{array}{l}\text { Bermuda } 3 \text { dedos acima do } \\
\text { joelho } \\
\text { Shorts no meio da coxa } \\
\text { Regata básica }\end{array}$ & $\begin{array}{l}\text { Calça montaria } \\
\text { Casacos estruturados/ } \\
\text { cinturados } \\
\text { Blazers }\end{array}$ \\
\hline
\end{tabular}

Fonte: Autor Ravena Locatelli (2014)

Desta maneira, define-se o real público-alvo da empresa Skarab como: mulheres de 25-45 anos, que pertencem à classe social $\mathrm{B}$, todas inseridas no mercado de trabalho de São Carlos e região. Na sua minoria com filhos pequenos e na maioria sem filhos ou 
com filhos já adultos. Equilibram sua vida pessoal e profissional com maestria e assumem com orgulho o caráter multitarefas que possuem. São seguras, femininas e contemporâneas, mínimas de pré-conceitos e que possuem valores, ideias e ideais, que as fazem enfatizar aspectos críticos e delicados na realidade e nos relacionamentos que vivem. Vestem do tamanho P-EG, e definem seu corpo morfologicamente: $45 \%$ ampulheta, $28 \%$ retângulo, $11 \%$ triângulo, $10 \%$ triângulo invertido e apenas $5 \%$ oval. Fazem escolhas de consumo de maneira consciente, compram pelo aspecto do produto e não por marca.

Detectou-se também no briefing da empresa estudada, a ausência de um vínculo maior do consumidor com os valores intangíveis dos produtos, de forma a valorizar o conceito de feminilidade e modernidade que a empresa deseja. Assim, entende-se que para que a marca tenha a consciência da imagem que projeta é necessário uma organização e orientação muito clara de seus princípios e abordagem de mercado, a partir do redirecionamento do público e do redesign da logomarca.

A marca representa o espírito do produto, pois, enquanto este é palpável e avaliado pela razão para atender às necessidades objetivas, a marca é capaz de transmitir emoção, seduzindo o consumidor com valores e atributos que falam direto às suas necessidades psicológicas (TREPTOW, 2013, p.59).

O redesign da logomarca, apresentado na Figura 1, a seguir, foi desenvolvido por uma dupla de designers gráficos que imergiram no contexto e histórico da empresa, público, imagem desejada, acompanhado da direção da empresa, com um olhar orientado pela gestão de design. 
Figura 1 - Redesign da marca.

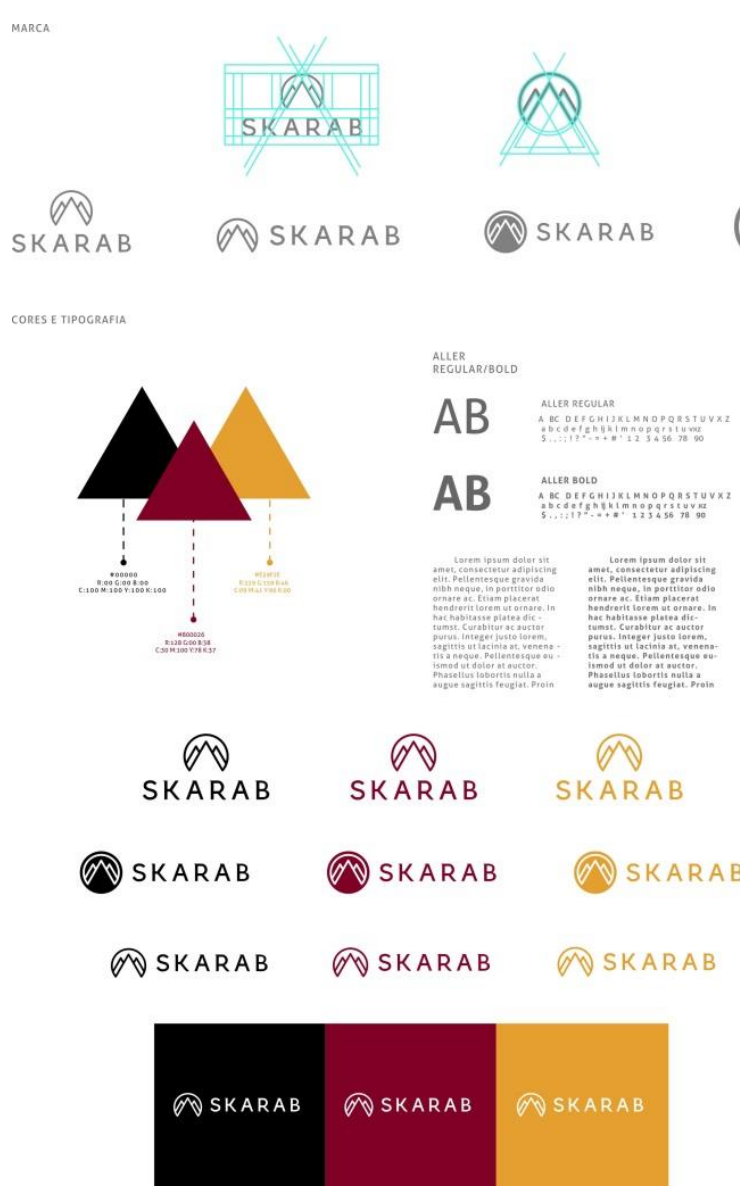

Fonte: Desenvolvimento Logo, Ana Luiza Frutuoso Bernardo e Pedro Pinotti

Além do redesign da marca, foram criados uma série de pontos de contato, interfaces responsáveis pela relação da marca com o consumidor, para proporcionar às pessoas uma experiência tangível com a marca (BEST, 2012, p.152).

\section{Síntese das ferramentas auxiliares}

Sob este contexto foram geradas e adaptadas algumas ferramentas, sínteses e técnicas que instrumentalizem o trabalho do designer, as especificidades da empresa. Estes elementos foram inseridos estrategicamente em etapas determinadas do novo processo projetual proposto à marca, na intenção de favorecer a relação do design com a empresa.

A primeira ferramenta consiste em uma planilha ou ficha de planejamento, constante no Anexo C, que é utilizada na primeira etapa para organizar de maneira 
programada os modelos a serem produzidos, a classificação de estilo, conteúdo de moda, tamanho, quantidade e estimativa de preço de venda.

A segunda ferramenta, também constante no Anexo C, constitui-se da adaptação de uma ficha síntese às especificidades da empresa. Esta é utilizada na etapa de especificação de projeto, momento em que há necessidade de delimitar um conceito gerador.

Outra ferramenta desenvolvida, utilizada na avaliação das alternativas geradas é a Ficha de Checagem e Aprovação de Modelo, igualmente constante no anexo C. Esta permite avaliar o modelo em seu contexto gerador, teor estético, rotativo (dentre a coleção), produtivo, mercadológico e financeiro.

Uma das ferramentas adaptadas, que ocasionou grande impacto na organização produtiva da empresa foi a Ficha Técnica, que contextualizou todas as informações necessárias para a produção do produto de maneira acessível, simples e sintética.

Além das ferramentas, supracitadas outras técnicas sistêmicas criativas foram inseridas no cotidiano produtivo da empresa, que de maneira esquemática podem ser melhores observadas no Anexo D.

\section{Considerações finais}

Martins e Merino (2008) apontam que o campo de atuação do design transcende a criação de produtos e peças gráficas como elementos isolados, passando a ser parte de um sistema e, consolidando-se como um processo de gestão. Ele (o design) possui a capacidade de alinhar aspectos tangíveis e intangíveis, como marca e produto físico; as necessidades de usuários e os atributos do produto, valor e custo; tecnologia e fator humano; ergonomia e produção; ergonomia e uso dos produtos, os materiais e as percepções.

Portanto, é importante estabelecer novas maneiras de gerir o processo de concepção e materialização dos produtos de vestuário de moda, criando mecanismos para registrar, disponibilizar, e facilitar a interpretação de informações e conhecimentos, de forma a auxiliar na tomada de decisões que resultem na diminuição de riscos e incertezas para estas empresas, especialmente MPE's, cujo cenário é de restrições de recursos. 
Este estudo evidenciou que, em geral, os modelos adotados por estas empresas, demonstram dificuldade em trabalhar com a complexidade que envolve $o$ desenvolvimento de produtos.

Observou-se a importância de estabelecer uma relação entre a gestão de design e o processo de desenvolvimento de produtos, ou seja, considerar a integração de ambas as atividades às outras variáveis que compõem o design de moda, contemplando a interação simultânea de tais conhecimentos com as três funções internas: a de concepção do produto; da materialização e manufatura e da comercialização dos mesmos.

Destaca-se que as ações dos profissionais envolvidos na implementação do processo projetual na referida MPE tornaram-se mais produtivas à medida que obtiveram as informações, por meio de tais ferramentas de comunicação, estimulando uma atitude mais proativa.

Artigo recebido em Outubro de 2015. Aprovado em Dezembro de 2015

DOI:http://dx.doi.org/105965/1982615×09012015004

\section{REFERÊNCIAS}

Best, K.. Fundamentos de Gestão do Design. Porto Alegre: Bookman. 2012.

Emídio, Lucimar F. Bilmaia. Modelo de Diagnóstico para Checagem de Utilização do Design por MPEs de Vestuário de Moda; uma ferramenta para estudos de casos. In: Pelos caminhos do Design: metodologia do projeto. Londrina: Eduel. pp. 511-535. 2012.

Gorb, Peter. Design Management. Nova Iorque: Van Nostrand, 1990

Martins, Rosane F. de Freitas; Van Der Linden, J. C. S.. In: Pelos Caminhos do Design: metodologia do projeto. Londrina: Eduel, pp. 11-15, 2012.

Martins, Rosane F. de Freitas; Merino, E.. A Gestão de Design como Estratégia Organizacional. Londrina: Eduel. 2008.

Mauri, Francesco. Progettare progettando strategia: il design del sistema prodotto. Milano: Dunod. 1996. 
Montemezzo, Maria Celeste F. Sanches. Diretrizes Metodológicas para o Projeto de Produto de Moda no Âmbito Acadêmico. 2003. Dissertação de Mestrado, UNESP, Bauru.

Mozota, B. B.. Gestão do Design: usando o design para construir valor de marca e inovação corporativa. Porto Alegre: Bookman, pp. 15-33, 2011.

Sanches, Maria Celeste F.. Projetando o Intangível: as ferramentas da linguagem visual no design de moda. In: Pelos caminhos do Design: metodologia do projeto. Londrina: Eduel, pp. 395-416, 2012.

Treptow, D.. Inventando Moda: planejamento de coleção. São Paulo: edição da Autora, 2013.

ANEXO A - Diagnóstico de checagem da utilização de design pela mpe.

\begin{tabular}{|c|c|c|}
\hline $\begin{array}{l}\text { Unidade de } \\
\text { Análise da } \\
\text { Pesquisa }\end{array}$ & Variáveis da Unidade de Análise & Respostas \\
\hline \multirow{5}{*}{$\begin{array}{l}\text { Dados da } \\
\text { Empresa }\end{array}$} & Segmento & Feminino, alguns modelos em tamanho plus size. \\
\hline & Número de funcionários & 10. \\
\hline & Tempo de atuação & 21 anos. \\
\hline & Produção mensal & $700-800$ peças. \\
\hline & Mercado de atuação & $\begin{array}{l}\text { Centro do estado de São Paulo: na cidade de São } \\
\text { Carlos e região. }\end{array}$ \\
\hline \multirow{4}{*}{$\begin{array}{c}\text { Estrutura } \\
\text { Organizacional }\end{array}$} & Poder de decisão na empresa & Centralizado \\
\hline & $\begin{array}{l}\text { Critérios utilizados para divisão do trabalho e os } \\
\text { mecanismos incorporados para coordená-los; }\end{array}$ & $\begin{array}{l}\text { Processo realizado pela proprietária de maneira } \\
\text { totalmente empírica. Divisão de tarefas realizada } \\
\text { a partir do reconhecimento das habilidades de } \\
\text { cada funcionário. }\end{array}$ \\
\hline & $\begin{array}{l}\text { Principal executivo da empresa/ funções } \\
\text { desempenhadas e sua formação; }\end{array}$ & $\begin{array}{l}\text { Proprietária. Formação em cursos técnicos de } \\
\text { modelagem e estilismo. Realiza todas as funções, } \\
\text { exceto a confecção dos produtos. }\end{array}$ \\
\hline & Cultura organizacional & $\begin{array}{l}\text { Mantém os mesmo valores e crenças e sistema } \\
\text { organizacional desde o início, porém busca se } \\
\text { atualizar tecnologicamente por meio de } \\
\text { maquinários e matéria-prima. }\end{array}$ \\
\hline \multirow{6}{*}{$\begin{array}{l}\text { Estratégias } \\
\text { Competitivas }\end{array}$} & Avaliação do grau de satisfação de seus clientes & $\begin{array}{l}\text { Por meio do sucesso de vendas e comentários } \\
\text { sobre os produtos. }\end{array}$ \\
\hline & $\begin{array}{l}\text { Como são monitoradas as forças externas do } \\
\text { macroambiente }\end{array}$ & $\begin{array}{l}\text { Observando o mercado e seu ritmo de } \\
\text { comercialização e dialogando com clientes. }\end{array}$ \\
\hline & Principal fator de competitividade da empresa & Modelagem de excelência. \\
\hline & $\begin{array}{l}\text { Como são trabalhadas as questões das mudanças } \\
\text { no ambiente industrial }\end{array}$ & $\begin{array}{l}\text { Investe-se em maquinários e aparelhos/ acessórios } \\
\text { para facilitar e melhorar processo de confecção. }\end{array}$ \\
\hline & Principal dificuldade de crescimento da empresa & Poder de decisão centralizado. \\
\hline & Postura da empresa em relação a concorrência & $\begin{array}{l}\text { Reativa, favorecida pela possibilidade do } \\
\text { atendimento imediato no fornecimento de } \\
\text { produtos. }\end{array}$ \\
\hline \multirow{2}{*}{$\begin{array}{l}\text { Ações de Design } \\
\text { Relacionadas ao } \\
\text { Processo de } \\
\end{array}$} & $\begin{array}{l}\text { Existência de um departamento de } \\
\text { desenvolvimento de produtos }\end{array}$ & Não. \\
\hline & Responsável pelo processo de desenvolvimento & Proprietária. \\
\hline
\end{tabular}




\begin{tabular}{|c|c|c|}
\hline \multirow{5}{*}{$\begin{array}{l}\text { Desenvolviment } \\
\text { o de Produto: } \\
\text { desenvolviment } \\
\text { o e organização } \\
\text { de atividades }\end{array}$} & de produto & \\
\hline & $\begin{array}{l}\text { Formação profissional de quem desenvolve esta } \\
\text { atividade na empresa }\end{array}$ & Cursos técnicos de modelagem e estilismo. \\
\hline & $\begin{array}{l}\text { Nível de interação do profissional designer ou da } \\
\text { equipe de design com outras áreas da empresa }\end{array}$ & Não há nenhum profissional da área na empresa. \\
\hline & $\begin{array}{l}\text { Metodologia/ procedimentos utilizada(os) pela } \\
\text { empresa no processo de desenvolvimento de } \\
\text { produto }\end{array}$ & $\begin{array}{l}\text { Aperfeiçoamento ou reprodução de produtos } \\
\text { existentes no mercado, por intermédio da } \\
\text { modelagem. Desenvolvimento a partir de pedidos } \\
\text { de clientes. }\end{array}$ \\
\hline & $\begin{array}{l}\text { Fontes de pesquisa utilizadas para o } \\
\text { desenvolvimento de produtos }\end{array}$ & $\begin{array}{l}\text { Observação do que predomina nas lojas do } \\
\text { mesmo segmento, revistas de moda e contato } \\
\text { direto com clientes. }\end{array}$ \\
\hline \multirow{6}{*}{$\begin{array}{c}\text { Ações de Design } \\
\text { Relacionadas ao } \\
\text { Processo de } \\
\text { Desenvolviment } \\
\text { o de Produto: } \\
\text { estratégia de } \\
\text { produto }\end{array}$} & O que diferencia o produto dos concorrentes & $\begin{array}{l}\text { Qualidade de matéria-prima e acabamento, } \\
\text { modelagem de excelência. }\end{array}$ \\
\hline & Decisão sobre novos produtos & Proprietária, alguns colaboradores da empresa. \\
\hline & $\begin{array}{l}\text { Como são trabalhados os elementos: } \\
\text { obsolescência programada da moda e o novo } \\
\text { como imperativo categórico }\end{array}$ & $\begin{array}{l}\text { Trabalha com lançamentos semanais de novos } \\
\text { produtos em pequena quantidade de peças por } \\
\text { modelo, objetivando maior variedade. Por este } \\
\text { motivo dificilmente são realizadas liquidações. }\end{array}$ \\
\hline & $\begin{array}{l}\text { Os projetos de produtos são desenvolvidos por } \\
\text { meio de: }\end{array}$ & $\begin{array}{l}\text { Aperfeiçoamento de produtos existentes: mesma } \\
\text { utilização em categorias diferentes. }\end{array}$ \\
\hline & Como dar competitividade ao produto & Modelagem de qualidade e diferenciada. \\
\hline & Importância da pesquisa de tendências & $\begin{array}{l}\text { Considera muito importante, mas a proprietária } \\
\text { declara que não tem tempo de executá-la. }\end{array}$ \\
\hline \multirow{4}{*}{$\begin{array}{c}\text { Papel da } \\
\text { atividade de } \\
\text { Design no } \\
\text { Desempenho da } \\
\text { Qualidade pelas } \\
\text { MPEs }\end{array}$} & Qualidade da matéria-prima antes da fabricação & $\begin{array}{l}\text { É realizado o controle de qualidade de maneira } \\
\text { superficial. }\end{array}$ \\
\hline & Qualidade durante o processo de fabricação & É realizado o controle de qualidade. \\
\hline & Teste de controle de qualidade & Não realiza testes de controle de qualidade. \\
\hline & Inspeção antes da distribuição dos produtos & Sim, é realizada a inspeção de cada peça. \\
\hline $\begin{array}{l}\text { Importância do } \\
\text { Design para a } \\
\text { Empresa }\end{array}$ & $\begin{array}{l}\text { Concepção de projeto, modelagem, produção, } \\
\text { distribuição e a comercialização }\end{array}$ & $\begin{array}{l}\text { Não executa um raciocínio projetual, enfatiza a } \\
\text { importância de uma boa modelagem. }\end{array}$ \\
\hline \multirow{8}{*}{$\begin{array}{l}\text { Nível de } \\
\text { Informação de } \\
\text { Design }\end{array}$} & $\begin{array}{l}\text { Possibilidades de atuação do profissional designer } \\
\text { de moda na empresa }\end{array}$ & Conhece parcialmente. \\
\hline & $\begin{array}{l}\text { Existência de um(a) profissional designer de } \\
\text { moda na empresa }\end{array}$ & Não. \\
\hline & $\begin{array}{l}\text { Atividades desempenhas pela designer na } \\
\text { empresa }\end{array}$ & Não dispõe de uma profissional designer. \\
\hline & $\begin{array}{l}\text { Entendimento da relação dos elementos da gestão } \\
\text { com o design, por parte da empresa }\end{array}$ & $\begin{array}{l}\text { Compreende que o conhecimento sobre design de } \\
\text { moda auxiliará na organização da empresa. }\end{array}$ \\
\hline & $\begin{array}{l}\text { O design é inserido na estratégia e no modelo de } \\
\text { gestão da empresa }\end{array}$ & ( \\
\hline & $\begin{array}{l}\text { Benefícios gerados pela adoção da gestão de } \\
\text { design como uma estratégia competitiva }\end{array}$ & $\begin{array}{l}\text { Será um fator diferenciador tanto para os produtos } \\
\text { e identidade de marca quanto para a gestão da } \\
\text { mesma. }\end{array}$ \\
\hline & Impacto de design no negócio da empresa & $\begin{array}{l}\text { Ocasionaria um alto impacto, pela quebra de } \\
\text { crenças e vícios. Porém, é estritamente } \\
\text { necessário, para o crescimento da empresa. }\end{array}$ \\
\hline & $\begin{array}{l}\text { Relação das questões de investimento e retorno } \\
\text { do design para a empresa }\end{array}$ & $\begin{array}{l}\text { Acredita que os benefícios são maiores } \\
\text { comparados ao investimento. }\end{array}$ \\
\hline
\end{tabular}

Fonte: Autora Lucimar Emídio; aplicação ao artigo Ravena Locatelli. 
ANEXO B - Novo processo projetual proposto à empresa.

Etapas

Ações

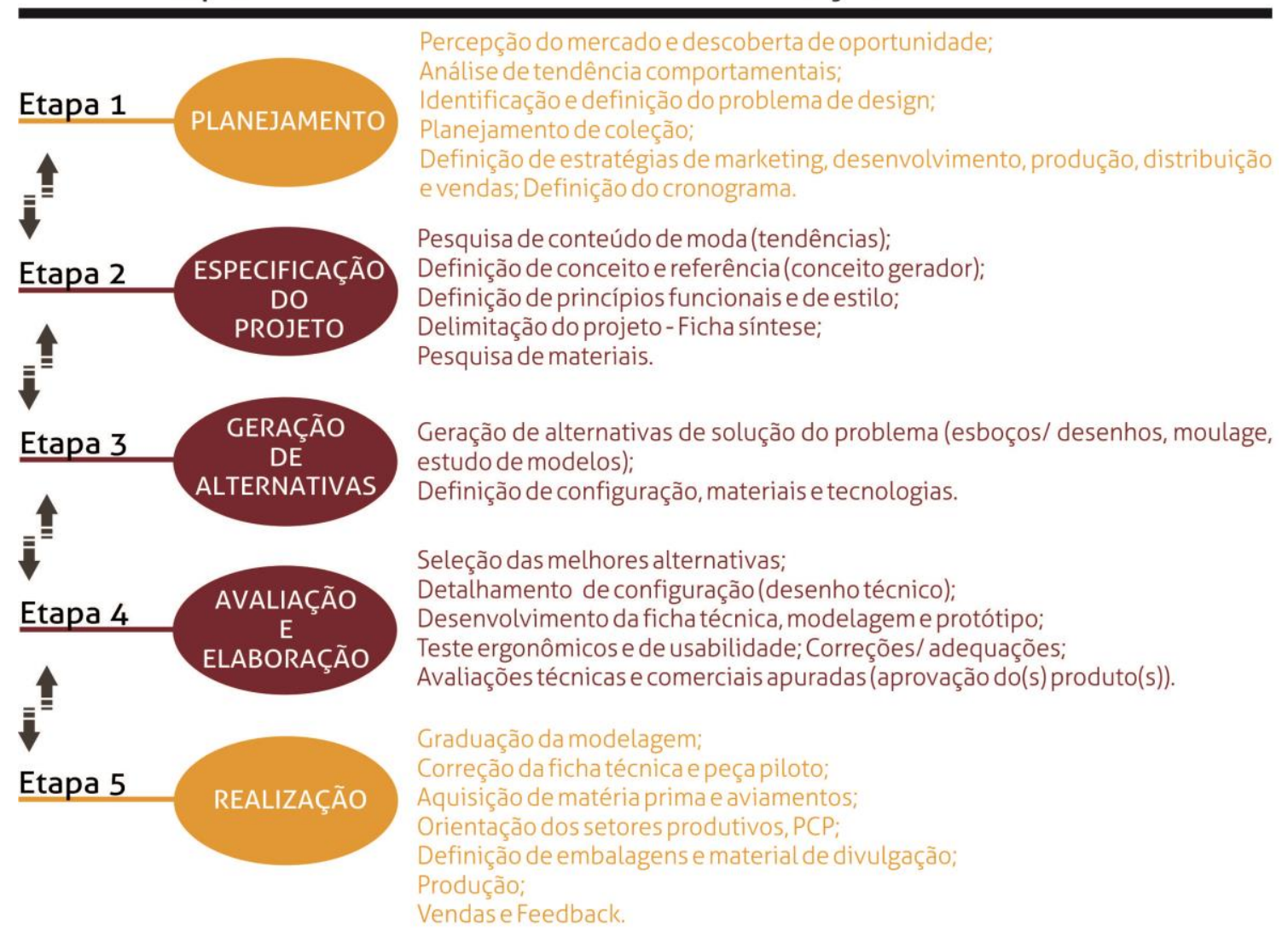

Fonte: Autor Ravena Locatelli 
ANEXO C - Ficha de planejamento; ficha sintese; ficha de checagem e aprovação de modelo.

\section{SKARAB}

\section{Planejamento de Coleção}

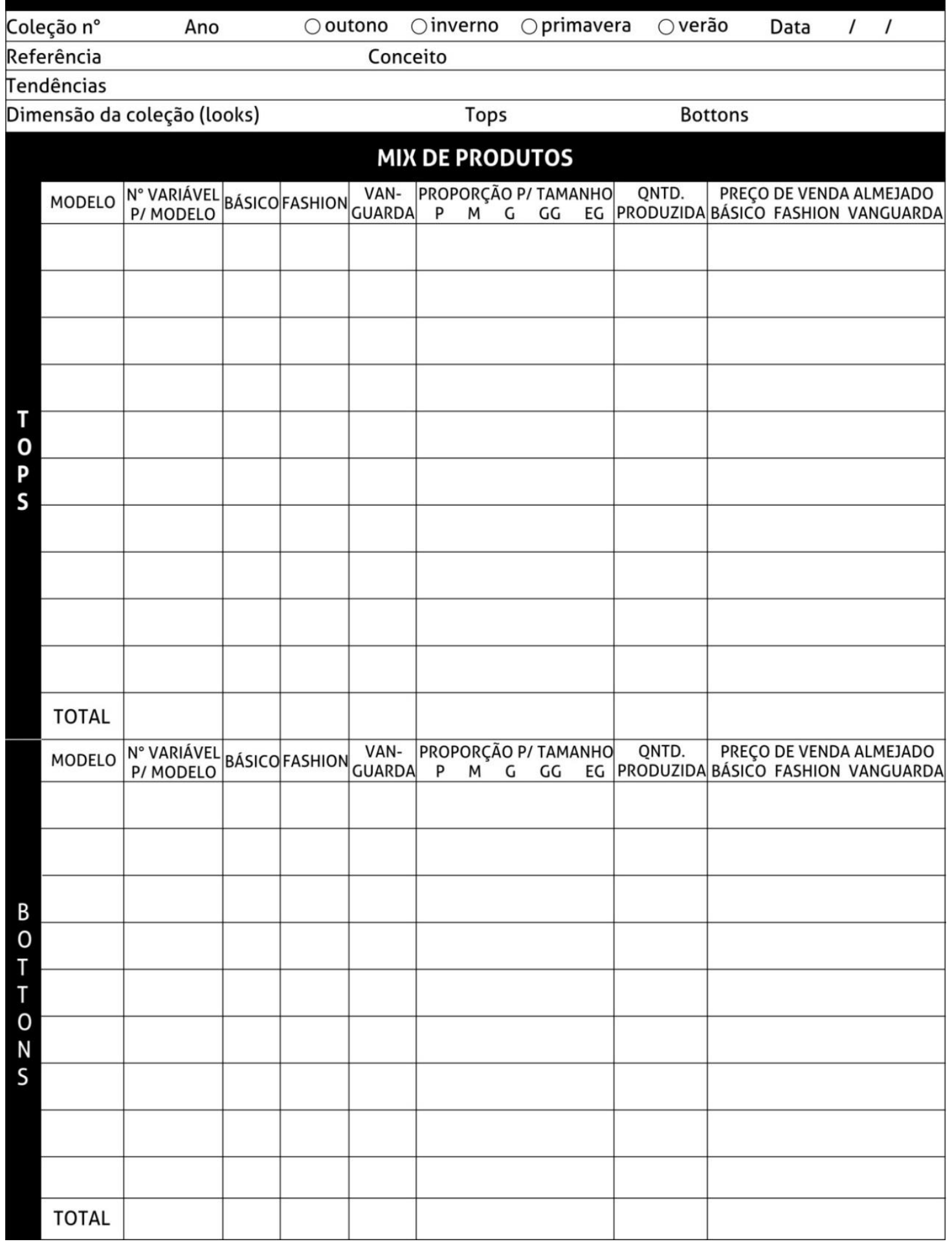

Fonte: Autor Ravena Locatelli 


\section{DSARAB}

Ficha Sintese

Coleção $n^{\circ} 001$ Ano 2015 Ooutono $\not$ inverno Oprimavera Overão Data 16/06/2014

Referência Amuletos de Sorte e Proteção

Conceito Feminilidade Contemporânea

Tendências EVOLUÇÃO DO SER: Quem sou eu? Nas profundezas, encontramos também o desconhecido, medos e inseguranças dão espaço às crenças e a uma nova forma de espiritualidade que passa a se tornar mais e mais cotidiana [...] Aspectos como a verdade, a honestidade e a transparência ganharam um novo patamar de importância no mercado e na vida das pessoas. É hora de repensar. Trata-se de uma consumidor que busca assuntos mais sérios, profundos, mas tratados com leveza e nostalgia.

\section{PROBLEMA}

Como inserir o design no contexto da marca Skarab, utilizando ferramentas de gestão de design e de metodologia projetual?

\begin{tabular}{l|l}
\hline \multicolumn{2}{|c|}{ NECESSIDADES } \\
\hline PRÁTICAS & ESTÉTICO-SIMBÓLICAS \\
-vestibilidade; & -contextualização urbana e moderna; \\
-versatilidade; & -ousadia sutil e refinada; segurança; \\
-fácil manutenção, qualidade e durabilidade dos produtos; & -a maior porcentagem da coleção deve favorecer a morfologia \\
de corpo do tipo ampulheta; & -cada peça deve conter o amuleto de referência de sua \\
-atentar-se às medidas de comprimento e circunferências de & idealização; \\
busto, cintura e quadril, assim como mangas e cavas e adequá- & -enfatizar o conceito de feminilidade e contemporaneidade da \\
las se necessário; & nova imagem da marca vinculando-o à logomarca. \\
-possibilitar rotatividade das peças entre os looks. &
\end{tabular}

\section{SÍNTESE IMAGÉTICA (painel semântico)}

TEXTURAS/ MATERIAIS

camurça

chiffon/ tecidos leves

couro

estampas com efeito blur

jacquard

bengaline

lã

IMPRESSÕES/ SENSAÇÕES

transparência da garrafa

forma da carranca (vertical e horizontal

enlace da figa

fendas e sobreposição

efeito brilho/ polido/ fosco -

contraste

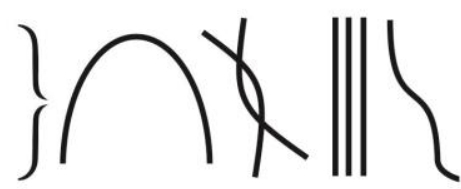

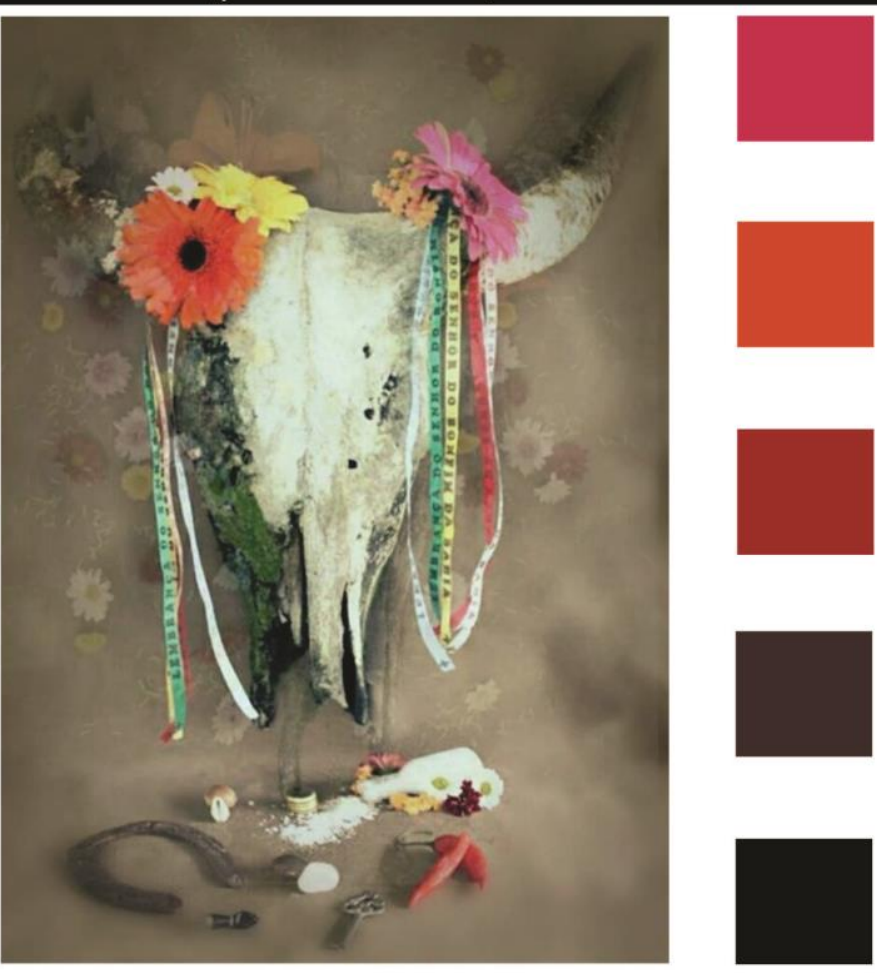

Fonte: Autor Ravena Locatelli 
W SKARAB

Checagem e Aprovação de Modelo

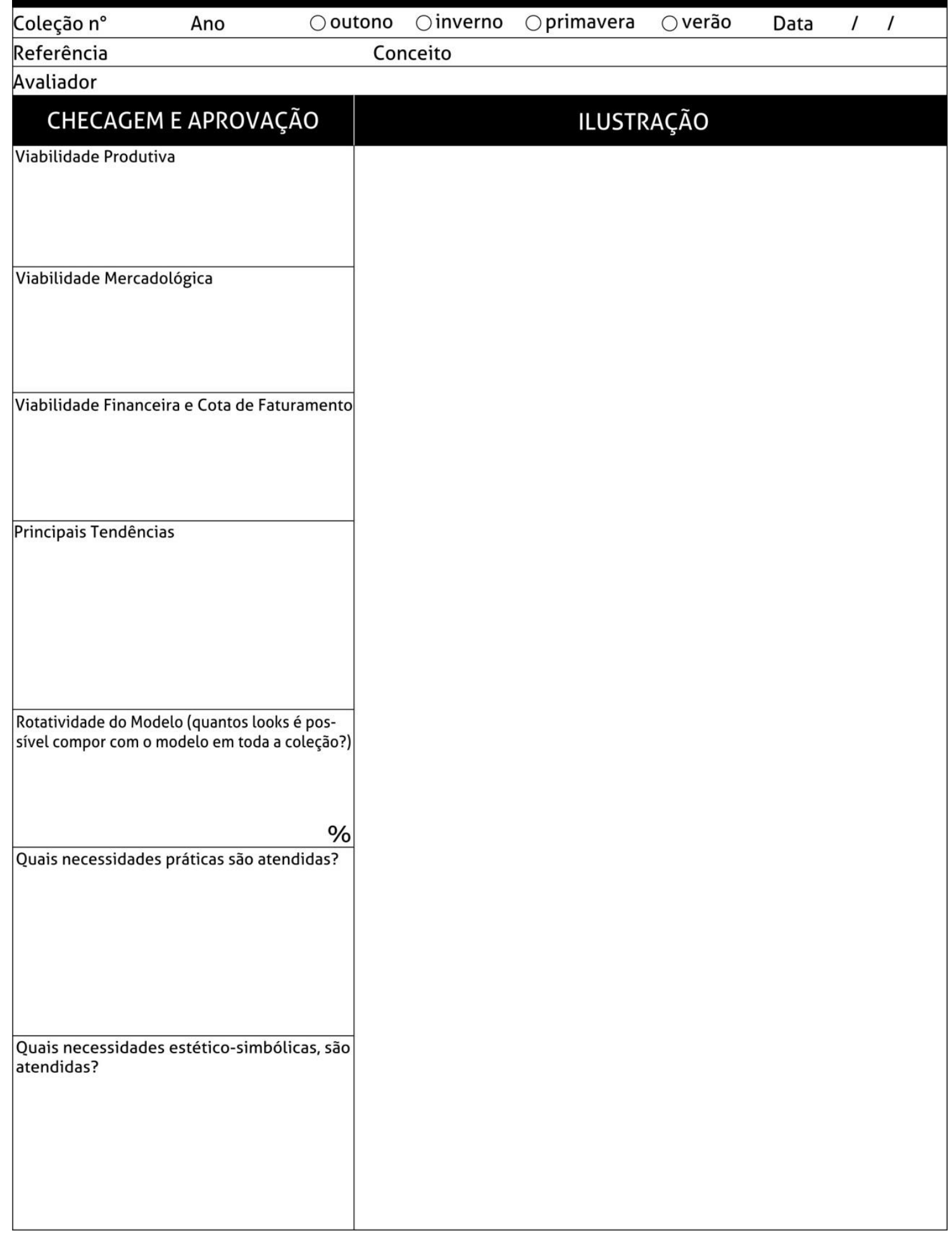

Fonte: Autor Ravena Locatelli 
ANEXO D - Legenda da aplicação de técnicas e sinteses. PRÓPRIA (2014)

\section{Etapas \\ Técnicas e Sínteses}

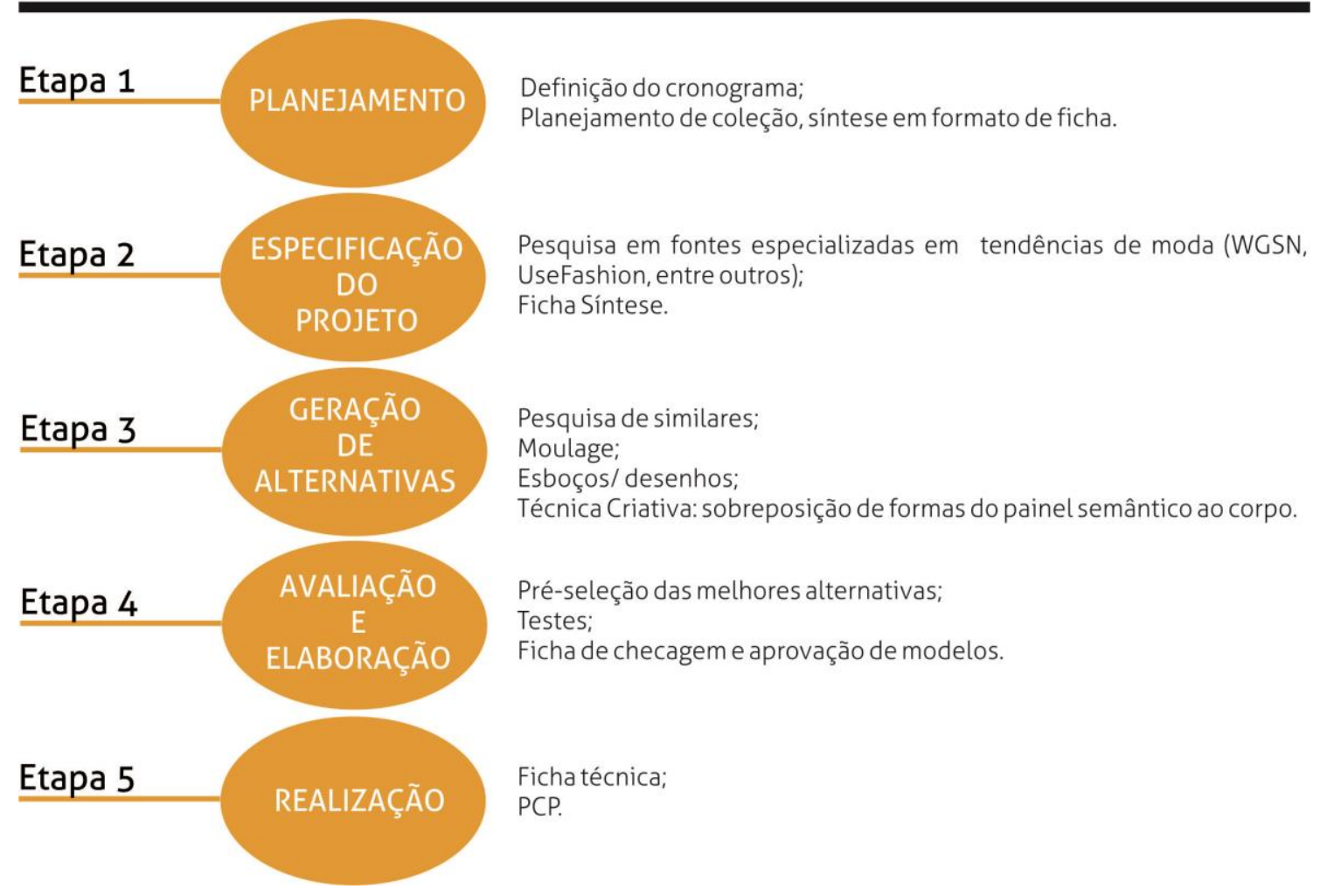

Fonte: Autor Ravena Locatelli 